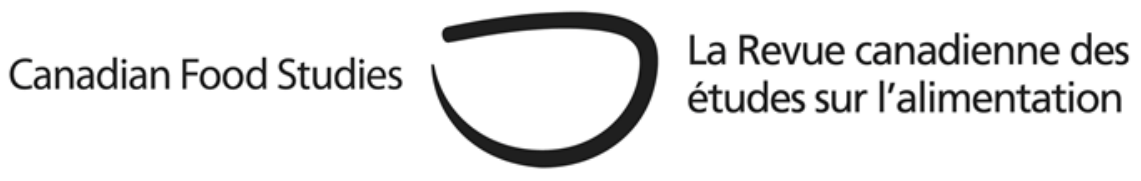

Book Review

\title{
Finance or food? The role of cultures, values, and ethics in land use negotiations
}

\author{
Edited by Hilde Bjorkhaug, Philip McMichael, and Bruce Muirhead \\ University of Toronto Press, 2020: 308 pages
}

Review by Amanda Shankland*

Throughout the latter half of the twentieth century, we saw a major shift in populations from rural areas to cities, and the development of large-scale farms mainly geared toward export markets. The neoliberal discourse of comparative advantage and the ensuing dramatic increases in food supply served as thin justification for this turn. The recession of 2008, however, put food security fears back on the menu and countries began to worry about the availability of arable land available for food production. At the same time, agricultural land was becoming hypercommoditized. Countries with excess farmland, like Canada and Australia, recognized the opportunity to profit off land investments, while speculators saw an opportunity to profit. A rush on agricultural land reduced supply and this was coincident with a rising demand for biofuels, all of which caused the value of farmland to rise steeply. Meanwhile, the discourse of neoproductivism reinforced the idea that producing enough food requires industrialized agriculture, a reliance on agrichemical corporations, large-scale value chains of producers and distributors, and a capital-intensive export-orientated system (Bjorkhaug et al., p.5). We have today a highly capitalized and complex agricultural system that contorts the global food system into a collection of financialized assets to be bought and sold, traded and swapped - a food system within which food has become an ancillary afterthought.

The important collection of essays in Finance or Food? looks at the kinds of values that have influenced investment decisions over land since the 2008 food crisis. As discussed in each of the essays, there are significant challenges with regard to the management of agricultural land. McMichael and Carson discuss issues around land grabbing and who should govern land. Essays by Clapp and Lawrence et al. look at private financial investment in agriculture and whether investment decisions should be left to the market. Brobakk and Muirhead ask if the rights of 
corporations should be considered to be as important as the rights of established farming communities in terms of land access. Ronningen discusses the key role smallholder farmers play in land management. Muirhead examines what role government plays in regulating investment regimes. Finally, Alvarez and Thorseth ask us what responsibility we have to future generations in terms of land use policy. The book also explores some of the important cultural dimensions around the issue of land use. The current emphasis on financialization of land and the industrialization of agriculture challenges the cultural values of many societies (Vinge \& Sorensen). Significantly, the book advances the important notion of a "socio-ecological commons culture", which is becoming an increasingly important alternative ontological approach to land management (McMichael et al., p. 282). Cultures that support communitycentered outcomes and strong ties to the environment provide a much stronger foundation for decision-making around land management.

Philip McMichael explores the consequences of "land grabbing" in efforts to secure land for food and biofuel production since the 2008 food crisis. He highlights the ways that the World Bank and the UN have often favoured the expansion of industrial agriculture over small-farmer agriculture (while often claiming to do just the opposite). Small-scale farmers are more concerned with long-term sustainability and they tend to better recognize ecological capital and the problem of "commodifying" nature. For instance, soil is recognized as a natural resource that not only needs to be preserved but built up. McMichael makes the important point that while the UN Committee on World Food Security (CFS) routinely recognizes the importance of smallscale agriculture, they frequently push farmers toward participating in the industrialized food value chain. The standard is to try to help small farmers participate in global value chains but given the regulations and international standards it is impossible for most small farmers to compete. They are then forced to sell their land (pp. 27-29).

Siri Granum Carson explains the ways that sovereign wealth funds, particularly pension funds, have accelerated financial speculation and land grabbing. She questions the ethical basis for the decisions made by many of these private investment firms. Similarly, Jennifer Clapp questions what is considered responsible or ethical agricultural investment. As voluntary guidelines begin to take over the investment environment, the limitations of those guidelines become increasingly clear. The authors remind us that small-scale farmers cannot access the credit they need to expand and compete in international markets. Further, they cannot afford to pay to meet the kinds of regulations that are imposed on them by other countries, particularly in Europe. Farmers have been forced to compete in the global supply chains through specialization, "value chaining", and contract farming; often with limited success.

Katrina Ronningen points out in her chapter on multifunctionality of agriculture in Europe, that we cannot ensure long term ecological restoration projects without societal support in maintaining land title for smallholders. The neoliberal narrative of "efficiency", neoproductivism, and "sustainable intensification" fails to draw attention to the multifunctionality and value of smallholder farms. There is a tendency to use the neoliberal discourse of "investment" to try to legitimize the devaluing of smallholder agriculture. 
Ronningen explains how pastoralists have taken on the language of environmentalists in order to challenge this discourse and gain the attention of the world. The social and cultural consequences of industrializing agriculture have been largely ignored, and so farmers look to highlight their role as "investors" in the biophysical welfare of land. McMichael, Carson, Clapp, and Ronningen all highlight the significant role that small famers can play in sustainable land management and the barriers they face. The focus on small-scale farmers in the book brings an important ethical dimension to the discussion around land rights.

The chapter by Lawrence, Sippel and Larder on investment in Australian agricultural land draws attention to the concern that foreign investors simply do not have enough of a stake in Australian rural communities or the environment. The Australian government has accepted heavy investment from companies in Canada, England, and the United States but has questioned the motives of Chinese and Gulf States investment because "food security" was cited as a reason for investment. The authors write that "when contestation occurred it was less directed to the geographical origin or motives of the companies but directed toward their interactions with local communities (p. 169)." In other words, they were not seen as a good "fit" (Lawrence et al., 2020, p. 169). The authors of the chapter seem to skirt around what is becoming a significant issue; the preference given to companies whose owners and operators are predominantly of European descent. The same unspoken truth holds in Canada, where the majority of farmers are white and entrance to farming is heavily guarded by barriers that have historically been imposed through the legacy of colonization.

Looking toward the future, the question of what is considered "ethical" land use investment is made all the more complex when we consider the possible implications for future generations. As Allen Alvarez and May Thorseth explain in their chapter, future generations and other species deserve to be included in any potential economic and ecological calculus of ethical land use practices. This final substantive chapter reminds us of our significant responsibility to future generations.

Speculation is identified as a major problem in the book. Blocking land grabs from some countries is often based on "cultural considerations." Many farmers and rural land holders in Australia, Canada, and the United States, however, want to see ownership remain primarily in the hands of white landowners. There is increasing recognition that these decisions often have racial undertones, but this issue is not discussed in the book. Nonetheless, the book still raises questions about the lasting impacts of colonization on our perceptions regarding what appropriate uses of farmland are, private ownership rights, and the financialization of agriculture. However, it does not go into any detail about the urgency of preserving agricultural lands based on cultural considerations. The preservation of Indigenous knowledge as being deeply tied to the land, for instance, is not discussed in the book. The case studies also generally deal with issues present within countries of the Global North. This is a noteworthy limitation for those looking for a more thoroughly global perspective. While the introduction and conclusion reference cognate issues in Africa, Asia, and South and Central America, the Global South remains largely absent from the case studies that comprise the bulk of the book. 
Jacob Muirhead writes that, "Neoliberalism is the political rationality of the current era, and it is no secret that it's guiding intellectual principles revolve around efficiencies of the market, the reduction of all social phenomena and choices to market-economic ones (p. 87)." A new ethical approach toward land reform must look to the social and ecological implications, for now and in the future. The book draws considerable attention toward this concern and as such is a significant contribution to the literature on agrarian land management.

Amanda Shankland is a PhD Candidate in the Department of Political Science at Carleton University. Her dissertation work looks at water governance in agricultural communities in rural New South Wales, Australia. Her areas of research expertise include social ecology, agroecology, food security, climate change, water management and rural development. 